\title{
KESIAPAN KADER DALAM MELAKSANAKAN PELAYANAN POSYANDU
}

\author{
Fatjrin Agustina, Ach. Rasyad, Sri Wahyuni \\ Universitas Negeri Malang, Jalan Semaramg 5 Malang 65145 \\ E-mail: fatjrina@yahoo.co.id
}

\begin{abstract}
The Readiness of Frameworks in Implementating Maternal and Child Health Centre Service (Posyandu). The purpose of this research is to know the readiness of the posyandu frameworks to do communicative serving, information serving, education serving, and the readiness of Posyandu frameworks to do posyandu serving using andragogis method at Posyandu in Pakisrejo Village, Srengat, Blitar. This research used quantitative descriptive method. Technic for collecting data of the research used questionnaire and documentary. The result of the research shows that almost half of the posyandu frameworks are ready to do communicative serving but need more preparation, less of half of the frameworks are ready to do informative serving, less of half posyandu frameworks are ready to do educative serving and more than half posyandu frameworks are very ready to do Posyandu serving using andragogis method at Posyandu in Pakisrejo Village, Srengat, Blitar.
\end{abstract}

Keywords: the readiness of frameworks, information serving, posyandu serving

\begin{abstract}
Abstrak: Kesiapan Kader Dalam Melaksanakan Pelayanan Posyandu. Penelitian ini bertujuan untuk mengetahui kesiapan kader dalam memberikan layanan komunikasi, layanan informasi, layanan edukasi dan kesiapan andragogis di Posyandu Desa Pakisrejo Kecamatan Srengat Kabupaten Blitar. Penelitian menggunakan rancangan kuantitatif dengan analisis deskriptif. Teknik pengumpulan data yang digunakan berupa angket dan dokumentasi. Hasil penelitian menunjukkan lebih dari separuh kader posyandu dinyatakan siap dalam memberikan pelayanan komunikasi, kurang dari separuh kader posyandu dinyatakan kurang siap dalam memberikan pelayanan informasi, kurang dari seraparuh kader posyandu dinyatakan siap dan lebih dari separuh kader posyandu dinyatakan sangat siap dalam memberikan pelayanan dengan menggunakan prinsip andragogis di Posyandu Desa Pakisrejo Kecamatan Srengat Kabupaten Blitar.
\end{abstract}

Kata kunci: kesiapan kader, layanan informasi, pelayanan posyandu

Posyandu merupakan salah satu tempat yang didirikan oleh ibu-ibu PKK, yang digunakan untuk memberikan pelayanan kesehatan dasar bagi para ibu yang memiliki anak usia 0-5 tahun. Pelayanan kesehatan dasar di posyandu adalah suatu upaya untuk meningkatkan berbagai layanan yang dibutuhkan oleh masyarakat seperti perbaikan gizi, pendidikan dan perkembangan anak, peningkatan ekonomi keluarga, ketahanan pangan keluarga dan kesejahteraan sosial. Beberapa pelayanan yang diberikan posyandu tersebut harus dijalankan sesuai dengan peraturan yang sudah ditetapkan. Apabila pelayanan yang ada dalam posyandu tersebut dapat berjalan dengan baik dan maksimal, maka dapat menunjang percepatan penurunan Angka Ke- matian Ibu (AKI), Angka Kematian Bayi (AKB) dan juga Angka Kematian Anak Balita (AKABA). Posyandu yang didirikan oleh suatu desa memiliki beberapa fungsi antara lain sebagai wadah pemberdayaan masyarakat dalam alih informasi dan keterampilan dari petugas kepada masyarakat dan antar sesama masyarakat dalam rangka mempercepat penurunan Angka Kematian Ibu (AKI), Angka Kematian Bayi (AKB) dan Angka Kematian Anak Balita (AKABA).

Fungsi tersebut dapat dijalankan dengan baik dan maksimal jika para kader posyandu memiliki kesiapan atau kompetensi yang memadai dalam melaksanakan pelayanan di posyandu tersebut. Selain memiliki beberapa fungsi, posyandu juga 
memiliki beberapa manfaat bagi masyarakat yaitu: (1) masyarakat memperoleh kemudahan untuk mendapatkan informasi dan pelayanan kesehatan dasar, terutama berkaitan dengan penurunan Angka Kematian Ibu (AKI), Angka Kematian Bayi (AKB) dan Angka Kematian Balita (AKABA); (2) masyarakat memperoleh layanan secara profesional dalam pemecahan masalah kesehatan terutama terkait kesehatan ibu dan anak; dan (3) masyarakat segera mendapatkan pelayanan kesehatan dasar terpadu dan pelayanan sosial lain yang terkait (Kementerian Kesehatan, 2011). Di dalam Pendidikan Luar Sekolah posyandu termasuk dalam pendidikan informal, khususnya dalam pendidikan keluarga.

Upaya pengembagan kualitas sumberdaya manusia dapat dilaksanakan secara merata, apabila sistem pelayanan kesehatan yang berbasis masyarakat seperti posyandu dapat dilakukan secara efektif, efisien dan dapat menjangkau semua sasaran yang membutuhkan layanan kesehatan anak, ibu hamil, ibu menyusui dan ibu nifas. Hal tersebut didukung oleh pendapat Aprilia (2013) bahwa keadaan akses masyarakat terhadap pelayanan kesehatan ibu sudah semakin membaik, hal berikut dibuktikan pada hasil Survey Demografi Kesehatan Indonesia (SDKI), menunjukkan bahwa: (1) dari 92\% tahun 2002 ibu hamil yang memeriksakan kehamilan ke tenaga kesehatan meningkat menjadi $96 \%$ tahun 2012; (2) dari $66 \%$ tahun $2002 \mathrm{ibu}$ bersalin dengan bantuan tenaga kesehatan meningkat menjadi $83 \%$ tahun 2012; dan (3) dari 40\% tahun 2002 ibu yang bersalin difasilitas pelayanan kesehatan meningkat menjadi 63\% tahun 2012 .

Tujuan penelitian ini adalah untuk mengetahui kesiapan kader posyandu dalam melaksanakan pelayanan posyandu khususnya Posyandu di Desa Pakisrejo Kecamatan Srengat Kabupaten Blitar. Penelitian ini diharapkan dapat menjawab akan kebutuhan kader Posyandu di Desa Pakisrejo Kecamatan Srengat Kabupaten Blitar, sehingga dapat dijadikan bahan masukkan untuk kader posyandu supaya lebih siap dalam melaksanakan pelayanan Posyandu di Desa Pakisrejo Kecamatan Srengat Kabupaten Blitar.

\section{METODE}

Rancangan penelitian ini menggunakan metode penelitian kuantitatif. Jenis penelitian yang digunakan adalah jenis penelitian deskriptif karena berusaha mendeskripsikan kesiapan kader dalam melaksanakan pelayanan Posyandu di Desa Pakisrejo Kecamatan Srengat Kabupaten Blitar. Penelitian deskriptif adalah suatu penelitian yang bertujuan untuk mendeskripsikan atau menggambarkan obyek yang diteliti melalui data sampel atau populasi, tanpa membuat kesimpulan yang berlaku untuk umum (Sugiyono, 2010). Populasi dalam penelitian ini adalah seluruh kader posyandu dengan jumlah sampel 20 kader Posyandu di Desa Pakisrejo Kecamatan Srengat Kabupaten Blitar.

Adapun teknik analisis data yang digunakan dalam penelitian ini yaitu menggunakan analisis data dengan rumus persentase. Fokus dalam penelitian ini adalah kesiapan kader dalam memberikan pelayanan komunikasi, kesiapan kader dalam memberikan pelayanan informasi, kesiapan kader dalam memberikan pelayanan edukasi dan kesiapan kader dalam memberikan pelayanan posyandu dengan menggunakan prinsip andragogis.

\section{HASIL}

Berdasarkan dari hasil distribusi frekuensi pada Tabel 1 jawaban kader mengenai kesiapan kader dalam melaksanakan pelayanan Posyandu di Desa Pakisrejo Kecamatan Srengat Kabupaten Blitar untuk kategori positif (yang ditunjukkan dengan jawaban selalu, sering dan pernah) diperoleh data: (1) aspek kader posyandu dalam memberikan pelayanan komunikasi sebanyak 55\%; (2) aspek kesiapan kader posyandu dalam memberikan pelayanan informasi sebanyak 46,7\%; (3) aspek kesiapan kader posyandu dalam memberikan pelayanan edukasi sebanyak 36\%; dan (4) aspek kesiapan kader posyandu dalam memberikan pelayanan posyandu dengan menggunakan prinsip andragogis di posyandu sebanyak $87,5 \%$.

Sedangkan jawaban kader dalam kategori negatif (yang ditunjukkan dengan jawaban kadangkadang dan tidak pernah) diperoleh data: (1) aspek kader posyandu dalam memberikan pelayanan komunikasi sebanyak 45\%; (2) aspek kesiapan kader posyandu dalam memberikan pelayanan informasi 
Tabel 1 Data Kesiapan Kader Dalam Melaksanakan Pelayanan Posyandu

\begin{tabular}{clcc}
\hline No & Kesiapan Kader dalam Melaksanakan Pelayanan Posyandu & $\sum$ ABC & $\sum$ DE \\
\hline 1 & Kesiapan kader posyandu dalam memberikan pelayanan komunikasi & $55 \%$ & $45 \%$ \\
\hline 2 & Kesiapan kader posyandu dalam memberikan pelayanan informasi & $46,7 \%$ & $53,3 \%$ \\
\hline 3 & Kesiapan kader posyandu dalam memberikan pelayanan edukasi & $36 \%$ & $64 \%$ \\
\hline \multirow{2}{*}{4} & $\begin{array}{l}\text { Kesiapan kader posyandu dalam memberikan pelayanan posyandu dengan } \\
\text { menggunakan prinsip andragogis }\end{array}$ & $87,5 \%$ & $12,5 \%$ \\
\hline \multicolumn{2}{c}{ Total } & $\mathbf{2 2 5 , 2 \%}$ & $\mathbf{1 7 4 . 8 \%}$ \\
\hline \multicolumn{2}{c}{ Total rata-rata } & $\mathbf{5 6 , 3 \%}$ & $\mathbf{4 3 , 7 \%}$ \\
\hline
\end{tabular}

Keterangan:

Kategori positif atau $\sum \mathrm{ABC}$

Kategori negatif atau $\sum \mathrm{DE}$

sebanyak 53,3\%; (3) aspek kesiapan kader posyandu dalam memberikan pelayanan edukasi sebanyak 64\%; dan (4) aspek kesiapan kader posyandu dalam memberikan pelayanan posyandu dengan menggunakan prinsip andragogis di posyandu sebanyak $12,5 \%$. Nilai jawaban terbesar yang berada pada kategori positif dengan persentase antara $50 \%$ s.d. $74 \%$, sehingga dapat dikatakan bahwa kader posyandu termasuk dalam kategori siap dalam melaksanakan pelayanan Posyandu di Desa Pakisrejo Kecamatan Srengat Kabupaten Blitar. Adapun hasil penelitian yang sudah dilakukan oleh peneliti mengenai kesiapan kader dalam melaksanakan pelayanan Posyandu di Desa Pakisrejo Kecamatan Srengat Kabupaten Blitar yaitu:

\section{Kesiapan Kader dalam Memberikan Pelayanan Komunikasi}

Kesiapan kader posyandu dalam memberikan pelayanan komunikasi di Desa Pakisrejo Kecamatan Srengat Kabupaten Blitar yaitu 5\% kader posyandu menyatakan selalu memberikan pelayanan dalam perbaikan kesehatan ibu hamil. Hal tersebut disebabkan karena pelayanan dalam perbaikan kesehatan ibu hamil bukan wewenang seorang kader. Selanjutnya kader posyandu yang menyatakan selalu memberikan pelayanan perbaikan gizi pada anak balita sebanyak 65\%. Dan 30\% kader posyandu menyatakan selalu memberikan pelayanan dalam perbaikan kesehatan pada bayi.

\section{Kesiapan Kader dalam Memberikan Pelayanan Informasi}

Kesiapan kader posyandu dalam memberikan pelayanan informasi di Desa Pakisrejo Kecamatan Srengat Kabupaten Blitar yaitu sebagai beri- kut: 70\% kader posyandu yang menyatakan selalu memberikan pelayanan mengenai pemberitahuan dalam pelaksanaan imunisasi dan pemberian vitamin pada seluruh anggota posyandu pada setiap hari buka posyandu. Temuan tersebut menunjukkan bahwa kader telah melaksanakan Tupoksi (Tugas Pokok dan Fungsi) sesuai yang dipersyaratkan sebagai jawaban Tupoksi kader yaitu pelayanan imunisasi di posyandu hanya dilaksanakan oleh petugas puskesmas. Kemudian 25\% kader posyandu yang menyatakan tidak pernah memberikan maupun menyampaikan informasi mengenai pentingnya deteksi dini pada tumbuh kembang bayi maupun anak balita.

\section{Kesiapan Kader dalam Memberikan Pelayanan Edukasi}

Kesiapan kader posyandu dalam memberikan pelayanan komunikasi di Desa Pakisrejo Kecamatan Srengat Kabupaten Blitar yaitu: kader posyandu yang menyatakan selalu memberikan materi mengenai pencegahan dan penanggulangan diare kepada seluruh anggota posyandu sebanyak $5 \%$. Dan $40 \%$ kader posyandu yang menyatakan tidak pernah memberikan materi mengenai penyesuaian jenis alat permainan edukatif anak usia dini pada anggota posyandu. Temuan tersebut menunjukkan bahwa kader posyandu belum maksimal dalam melaksanakan Tugas Pokok dan Fungsi (Tupoksi) yang sudah di persyaratkan sebagai jawaban Tupoksi kader posyandu yaitu pelaksanaan pelayanan posyandu bayi dan balita dalam bentuk kegiatan yang bersifat kreativitas dan untuk meningkatkan tumbuh kembangnya, maka diperlukan ruang pelayanan yang memadai yakni ruang yang berisi berbagai jenis sarana permainan 
penunjang kreativitas dan tumbuh kembang anak yang disesuaikan dengan umur balita.

Kader posyandu yang menyatakan tidak pernah memberikan materi mengenai cara merawat bayi sejak dini kepada anggota posyandu khususnya bagi ibu-ibu muda sebanyak 55\%. Kesiapan kader posyandu dalam memberikan pelayanan posyandu dengan menggunakan prinsip andragogis di Desa Pakisrejo Kecamatan Srengat Kabupaten Blitar yaitu $15 \%$ kader posyandu yang menyatakan selalu melakukan kerjasama dengan seluruh anggota posyandu untuk meningkatkan kualitas pelayanan kesehatan dasar yang diberikan oleh kader posyandu. Sebanyak $70 \%$ kader posyandu yang menyatakan selalu memberikan kepercayaan kepada kader yang lain dalam hal memberikan pelayanan kesehatan dasar bagi seluruh anggota posyandu.

Pada materi berikutnya tidak ada kader posyandu yang menyatakan kadang-kadang memberikan pelayanan kesehatan dasar pada anggota posyandu dengan penuh keceriaan, 5\% kader posyandu yang menyatakan kadang-kadang mampu menerima kritikan dan saran ketika memberikan pelayanan kesehatan dasar pada anggota posyandu, 10\% kader posyandu menyatakan kadang-kadang tetap melakukan komunikasi yang baik kepada anggota posyandu yang kurang aktif dalam mengikuti kegiatan posyandu.

\section{PEMBAHASAN}

Pelayanan komunikasi yang diselenggarakan untuk ibu hamil yang antara lain pemeriksaan kesehatan ibu hamil yang termasuk perencanaan Persalinan dan Pencegahan Komplikasi (P4KI) serta $\mathrm{KB}$ pasca persalinan yang dilakukan oleh tenaga kesehatan yang dibantu oleh kader dan apabila ditemukan kelainan, segera dirujuk ke puskesmas (Kementerian Kesehatan, 2011). Jenis imunisasi yang diberikan disesuaikan dengan program terhadap bayi dan ibu hamil (Kementerian Kesehatan, 2011). Kader posyandu dalam melaksanakan pelayanan posyandu diwajibkan memiliki kesiapan-kesiapan. Kesiapan adalah tingkat sampai mana orang memiliki kemampuan dan kesediaan untuk menyelesaikan tugas tertentu (Robins, 2008). Untuk menunjang pelaksanaan pelayanan kesehatan dasar yang antara lain kesiapan teknis kader posyandu dan kesiapan kader posyandu dalam melaksanakan pelayanan dengan menggunakan prinsip andragogis.

Kesiapan teknis kader posyandu dalam memberikan pelayanan kesehatan dasar, meliputi kesiapan kader posyandu dalam memberikan pelayanan komunikasi, kesiapan kader posyandu dalam memberikan pelayanan informasi, kesiapan kader posyandu dalam memberikan pelayanan edukasi, dan kesiapan kader posyandu dalam melaksanakan pelayanan posyandu dengan menggunakan prinsip andragogis di Posyandu (Darmawan \& Setya, 2009). Selain itu, dengan ruang yang memadai diharapkan balita tidak hanya digendong orangtuanya saja akan tetapi bisa dilepas bermain dengan sesama balita dengan pengawasan kader, hal seperti ini diharapkan dapat memaksimalkan proses pelayanan posyandu yang diberikan kepada bayi maupun anak balita tersebut (Kementerian Kesehatan, 2011). Hal tersebut perlu ditindaklanjuti dengan pembinaan dan pelatihan kader dalam bentuk pendidikan bagi balita, seperti Pendidikan Anak Usia Dini (PAUD) (Muntoha, 2015).

Beberapa prinsip pembelajaran dalam merespon kondisi belajar orang dewasa yang salah satunya ialah berusaha membina hubungan kepercayaan dan kerja sama diantara sesama peserta belajar (Basleman, 2011). Kesiapan kader dapat ditingkatkan melalui pelatihan kader terutama pada pengelolaan Posyandu (Purnomo, 2015). Selain kesiapan kader, kesiapan sarana fisik di Posyandu juga perlu dilihat dari lima variabel yaitu, sarana fisik, peralatan dan logistik, pembiayaan, perencanaan, dan pengawasan (Ayuningtyas, 2008). Kesiapan dalam lima variabel itu nantinya akan digunakan untuk pengemabngan Posyandu sebagai bagian dari Pos Pelayanan Kesehatan di Desa Pakisrejo. Perkembangan ini nantinya dapat digunakan dalam mempersiapkan desa Pakisrejo menjadi Desa Siaga (Prasodjo, 2010).

Menurut Joesoef (2008) pendidikan informal adalah pendidikan yang diperoleh seseorang dari pengalaman sehari-hari dengan sadar atau tidak sadar, sejak seseorang lahir sampai mati, di dalam keluarga, dalam pekerjaan maupun pengalaman sehari-hari. Peran pendidikan luar sekolah dalam pelaksanaan posyandu yaitu sebagai resource lingker (penghubung sumber), dengan adanya resource lingker, posyandu dapat memperoleh 
informasi yang disampaikan oleh petugas puskesmas dalam memberikan sosialisasi kepada peserta posyandu mengenai informasi kesehatan dasar pada anak balita, pemberian gizi yang baik dan tepat bagi anak balita, program KB dan lain sebaginya, karena tidak semua kader posyandu dapat memberikan sosialisasi kepada peserta posyandu. Sehingga dibutuhkan peran pendidikan luar sekolah sebagai resource lingker antara posyandu dengan puskesmas. Selain sebagai resource lingker, peran pendidikan luar sekolah dapat memberikan pelatihan mengenai kesiapan kader dalam melaksanakan program posyandu dengan maksimal sehingga para kader yang mengikuti pelatihan tersebut dapat memiliki bekal dalam melaksanakan kegiatan posyandu.

\section{SIMPULAN DAN SARAN}

Berdasarkan pembahasan sebelumnya, maka dapat disimpulkan bahwa lebih dari separuh kader posyandu dalam memberikan pelayanan komunikasi di Posyandu Desa Pakisrejo Kecamatan Srengat Kabupaten Blitar dinyatakan siap tetapi belum maksimal dengan indikator bahwa setiap kader harus lebih aktif lagi dalam berkomunikasi dengan anggota posyandu. Kurang dari separuh kader posyandu dalam memberikan pelayanan informasi di Posyandu Desa Pakisrejo Kecamatan Srengat Kabupaten Blitar dinyatakan siap dengan indikator bahwa kader posyandu jarang melaksanakan pelayanan informasi yang disebabkan oleh para kader posyandu yang kurang aktif dalam pemberitahuan mengenai informasi kesehatan ibu dan anak, ibu hamil dan lain sebagainya.

Kurang dari separuh kader posyandu dalam memberikan pelayanan edukasi di Posyandu Desa Pakisrejo Kecamatan Srengat Kabupaten Blitar dinyatakan siap karena kader posyandu dalam memberikan pelayanan edukasi hanya berperan sebagai pembantu bidan atau petugas yang berwenang dalam memberikan pelayanan edukasi tersebut. Lebih dari separuh kader posyandu dalam memberikan pelayanan dengan menggunakan prinsip andragogis di Posyandu Desa Pakisrejo Kecamatan Srengat Kabupaten Blitar dinyatakan sangat siap karena sebagian besar kader posyandu selalu memberikan pelayanan dengan menggunakan prinsip andragogis dengan baik sesuai dengan kebutuhan anggota posyandu.
Saran yang dapat dilakukan oleh kader posyandu dalam melaksanakan pelayanan di Posyandu Desa Pakisrejo Kecamatan Srengat Kabupaten Blitar adalah kesiapan kader posyandu dalam memberikan pelayanan komunikasi dapat dinyatakan siap tetapi masih belum maksimal sehingga perlu ditingkatkan kembali. Oleh karena itu disarankan agar kader posyandu mengetahui berbagai macam bahasa baik bahasa daerah maupun bahasa yang lain sehingga kemampuan berkomunikasi menjadi lebih baik dan mudah untuk difahami. Kesiapan kader posyandu dalam memberikan pelayanan informasi perlu ditingkatkan kembali karena kurang dari separuh kader posyandu siap dalam memberikan pelayanan informasi. Oleh karena itu, disarankan agar para kader lebih banyak membaca buku panduan untuk kader posyandu.

Kesiapan kader posyandu dalam memberikan pelayanan edukasi masih perlu ditingkatkan kembali karena kurang dari separuh kader posyandu siap dalam memberikan pelayanan edukasi. Oleh karena itu disarankan agar desa atau puskesmas mengadakan pelatihan untuk para kader posyandu mengenai kesiapan kader dalam melaksanakan pelayanan di posyandu. Perlu disediakanya sarana prasarana yang memadai untuk digunakan dalam melaksanakan pelayanan di posyandu supaya anggota posyandu mendapatkan pelayanan kesehatan yang maksimal di posyandu tersebut. Perlu adanya penelitian berikutnya mengenai kesiapan kader posyandu dalam melaksanakan pelayanan di posyandu dengan populasi yang berbeda untuk mengetahui apakah nantinya terdapat perbedaan hasil dengan yang dilakukan dalam penelitian ini karena tidak semua kader posyandu memiliki kesiapan yang sama dalam melaksanakan pelayanan di posyandu.

\section{DAFTAR RUJUKAN}

Aprilia, R. 2013. Menkes: Angka Kematian Ibu di Indonesia, Mari Turunkan Segera, (Online), (viva new: http://nasional.news.viva.co.id/news/ read/459389-menkes--angka-kematian-ibu-diindonesia--mari-turunkan-segera), diakses 17 Agustus 2014.

Anisah, B., \& Mappa, S. 2011. Teori Belajar Orang Dewasa. Bandung: PT Remaja Rosda Karya.

Ayuningtyas, D. 2008. Analisis Kesiapan Pos Kesehatan Desa dalam Pengembangan Desa 
Siaga di Kabupaten Kepulauan Mentawai Provinsi Sumatera Barat Tahun 2008. Jurnal Manajemen Pelayanan Kesehatan, 11(3), 2329.

Darmawan, \& Surya, E. 2009. Tinjauan Kebijakan Terkait Pengelolaan Posyandu sebagai Masukan Dalam Perumusan Peran dan Tanggung Jawab Departemen Kesehatan dalam Pengelolaan Posyandu. Makalah disampaikan dalam Lokakarya Perumusan Peran dan Tanggung Jawab Departemen Kesehatan dalam Pengelolaan Posyandu (Workshop on Formulation of Roles and Responsibilities of the Department of Health in the Management of Posyandu), Departemen AKK FKMUI.

Joesoef, S. 2008. Konsep Dasar Pendidikan Luar Sekolah. Jakarta: PT Bumi Aksara.

Kementerian Kesehatan. 2011. Pedoman Umum Pengelolaan Posyandu. Jakarta: Kementerian Kesehatan.
Muntoha, M. 2015. Pembinaan dan Pelatihan Kader Pengurus dan Pengelola Baru Pendidikan Anak Usia Dini (PAUD) Cerdas Dusun Bandung dan Dusun Songbanyu 1 Kecamatan Songbanyu, Gunung Kidul Daerah Istimewa Yogyakarta. Asian Journal of Innovation and Entrepreneurship, 4(3), 166-171.

Prasodjo, R. S. 2010. Pemetaan Kesiapan Desa Menuju Desa Siaga di Lima Provinsi. Jurnal Ekologi Kesehatan, 9(3), 1248-1253.

Purnomo, G. A. 2015. Pengaruh Pelatihan Kader tentang Posyandu terhadap Kemampuan Pengelolaan Posyandu di Desa Sendangsari Kecamatan Pengasih Kulon Progo. Yogyakarta: STIKES Aisyiyah Yogyakarta.

Robins, P. S. 2008. Perilaku Organisasi. Jakarta: Salemba Empat.

Sugiyono. 2010. Metode Penelitian Pendidikan Pendekatan Kuantitatif, Kualitatif dan $R \&$ $D$. Bandung: Alfabeta. 